\title{
NOTE SUR LA CULTURE IJU LUPIN (ORDINAIRE ET DOUX)
}

\author{
par P. CHIMITS \\ Ingenieur Agronorne, Inspecteur des Eaux et Forets, \\ et S. KRECZMER \\ Ingénieur Agronome S. G. G. W. de Varsovie.
}

Le Jupin est bien connu dea pisciculteurs allemands et polonais qui l'utilisent tant en engrais vert (pendant les périodes d'assec de leurs étangs) que pour la graine (qui entre pour une part importante dans les rations d'engraissement de la Carpe).

Il est encore pratiquement inconnu en France. Des essais vont être entrepris cetle année sur une variété nouvelle, le lupin doux ou lupin sans lupinine.

La longue expérience de l'un de nous qui l'a longtemps cultivé en Pologne a permis d'établir cette note qui pourra rendre service à ceux qui, cette année, et sous notre contrôle, exécuteront ces essais dans diverses régions d'étangs frạnçaises.

Dans les pays à sols légers et paures, on emploie depuis longtemps le lupin dans les assolements.

Le lupin est une légumineuse à très faibles exigences en ce qui concerne le sol et l'eau ; toutefois, une certaine humidité est nécessdire au moment de la germination. On peut dire que le lupin doux est la luzerne des teries pauvreg.

Le lupin ondinalre. - On semail le lupin pour obtenir soit de l'engrais vert, apportant au sol de l'azote et une grande masse de matière organiques, soit de la graine.

La paille et les cosses, malgré leurs richesses en azote, étaient seulement employées comme nourriture pour les moutons, car elles contiennent de la lupinine, alcaloïde toxique et de gout amer.

La graine de lupin est très riche en protéinęs (34\%) mais, contenant beaucbup de lupinine, ne pouvait ètre utilisée directement comme aliment du bétail. On lutilisait toutefois comme nourriture pour les poissons d'étangs, et notamment pour la Carpe.

On chercha naturellement à éliminer la lupinine pour utiliser la graine de lupin si riche en protéine. Le procédé suivant était utilisé avec bon résultat.

On trempait les graines non concassées dans de l'eau tiède pendant 48 heures. On les cuisait ensuite une demi-heure à la vapeur, puis on les 
plaçait dans des caisses à claires-voies plongées 48 heures dans l'eau courante. La graine était ainsi pratiquement débarrassée de la lupinine et pouvait être donnée aux boving et mème au chevaux.

On distingue les espèces de lupin suivantes:

- Le lupin jaune : utilisé dans les sols les plus secs et les plus Iégers ;

- Le lupin blanc : dans les sols un peu moins légers ;

- Le lupin rouge : dans les sols un peu plus lourds ;

- Le lupin bleu : dans les sols plus compacts et argileux.

Le Lupin doux ou says Lupinixe. - Quelques années avant la guerre de 1939 , on a commencé à utiliser une variété de lupin sans lupinine ou lupin doux qu'on était parvenu à sélectionner, mais qui, malheureusement, i tendance - au bout de plusieurs générations - à s'enrichir en lupinins:-

Le lupin doux peut être utilisé directement comme tourrage vert et comme ensilage, ainsi que sa graine qui contient 30 à $34 \%$ de protéine.

Sur le $3 \%$ de cellulose que contient le fourrage vert, $2,2 \%$ sont assimilableg.

En fourrage vert, le lupin doux a seulement $0,4 \%$ de protéine de moing que la luzerne.

Engrais et façons culturales. - Bien que ses exigences au point dy vue du sol soient très modestes, le lupin ne supporte ni les sols mouilleux, ni les sols calcaires. Il est à proscrire dans ces deux cas.'

Les engrais potassiques (sylvinite ou chlorure) et phosphatés (superphosphates de préférence aux scories) augmentent sensiblement le rendement.

Si le lupin est cultivé pour le fourrage, on épandra à l'hectare i 50 kilos de chlorure de potassium et Ioo kilos de superphosphates. Si le lupin est cultivé pour la graine, on épandra jo kilos de chlorure de potassium, seulement, et 1 jo kilos de superphosphates.

Si possible, à l'automne, on pratiquera un labour moyen. En tous cas, au printemps, en mars, on épand les engrais, on herse et on sème. Le semis aura lieu fin mars, début avril, le plus tôt possible, mais toutefois quand les fortes gelées ne sont plus à craindre.

On sème par hectare, à raison de 80 à I ro kilos à l'hectare (selon la richesse du sol) pour obtenir des graines, et à raison de r 30 à 180 kilos pour obtenir du fourrage. Le semis se fait à un centimètre de pnofondeur. car le lupin a une germination épigée et souffrirait d'un enfouissement plus profond.

Développement et hécolte. - En 1948, dans une pépinière de la forêt du Der et un bassin de grossissement des étangs du Der, l'Inspecteur des Eaux et Forêts Rabouirle a fait un essai encourageant de culture de lupin pour engraisser le sol avant repiquage de semis de plants forestiers, danz le premier cas, et avant mise en eau dans le second. 
Le lupin, au début, se développe lentement, puis part très vitc, couvre complètement le sol, étouffe les mauvaises herbes et présente une énorme masse de fourrage, très dense, et haut de $0 \mathrm{~m}$. 60 à 1 mètre.

pour obtenir le fourrage vert dans les meilleures conditions, on fauche lc lupin doux rquand il commence à fleurir. On peut alors, soit le donner immédiatement aux bêtes, soit l'ensiler: Il ne peut ètre transformé en foin.

Pour obtenir la graine, il faut attendre le moment où les cosses ne sont pas encore complètement múres, où les grains sont encore verts et où ils commencent à se marbrer légèrement.

On coupe le lupin à la moissonneıse, et on en fait des tas, les cosses étant placées au centre à l'abri du soleil, pour qu'elles sèchent sans s'ourir. On les rentre ensuite, si possible le matin, avant que la rosée soit évaporée, et on les bat.

Si l'on opère à la moissonncuse-batteuse, on laisse mùrir le lupin debout avant de le récolter.

Deux points particuliers doivent être signalés :

- Comme toutes les légumineuses, lit présence de bactéries fixatrices d'azote est nécessaire à la bonne végétation du lupin.

Dans le cas où le sol est complètement dépourvu de telles bactéries, il est recommandé d'épandre, avant le semis, un peu de terre provenant d'une parcelle cultivée au lupin l'année précédente.

- Il ne faut, en aucun cas, cultiver le lupin dioux a proximité du Iupin ordinaire, afin d'éviter la fécondation croisée, et l'apparition de lupinine dans le lupin doux.

Culture en asseg n'étang. - Le lupin ordinaire est un excellent engrais vert en culture d'assec dans les étanırss à sol sableux, secs et dépourvus de végétation.

Le labour d'automne sera, en ce cas, difficilement praticable. Il suffira simplement d'un coup de canadienne au printemps.

Si le sol est enherbé, un labour printanier avant le scmis sera nécessairc.

Conclusion. - Le lupin doux est encroe pratiquement inconnu en France.

Les premières qraines, à notre connaissance, ont été rapportées d'Allèmagne en 1945 , à la fin des hostilités, par un élève ingénieur agronome M. François Chimits.

Grâce à l'intervention de M. l'Inspecteur général Gatheron et de M. DE Vaugelas, dir Cabinet du ministre de l'Agriculture, quelques tonnes de semence de lupin sont en cours d'importation de Hollande, pour que des essais de culture soient entrepris dans diverses régions naturelles à sol pauvre. 